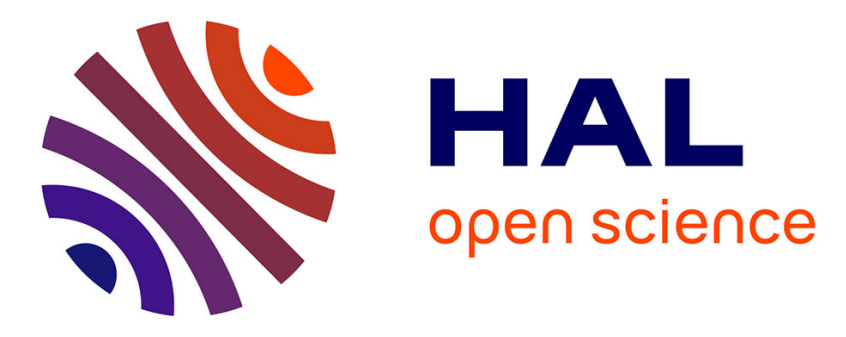

\title{
Preyssler Heteropoly Acids Encapsulated in a Silica Framework for an Efficient Preparation of Fluorinated Hexahydropyrimidine Derivatives under Solvent-Free Conditions
}

Angel G. Sathicq, Diego M. Ruiz, Thierry Constantieux, Jean Rodriguez, Gustavo P. Romanelli

\section{To cite this version:}

Angel G. Sathicq, Diego M. Ruiz, Thierry Constantieux, Jean Rodriguez, Gustavo P. Romanelli. Preyssler Heteropoly Acids Encapsulated in a Silica Framework for an Efficient Preparation of Fluorinated Hexahydropyrimidine Derivatives under Solvent-Free Conditions. SYNLETT, 2014, 25 (6), pp.881-883. 10.1055/s-0033-1340845 . hal-01066292

\section{HAL Id: hal-01066292 https://hal.science/hal-01066292}

Submitted on 20 Mar 2015

HAL is a multi-disciplinary open access archive for the deposit and dissemination of scientific research documents, whether they are published or not. The documents may come from teaching and research institutions in France or abroad, or from public or private research centers.
L'archive ouverte pluridisciplinaire HAL, est destinée au dépôt et à la diffusion de documents scientifiques de niveau recherche, publiés ou non, émanant des établissements d'enseignement et de recherche français ou étrangers, des laboratoires publics ou privés. 


\title{
Efficient Preparation of Fluorinated Hexahydropyrimidine Derivatives under Solvent-Free Conditions
}

\author{
Ángel G. Sathicq, ${ }^{* a}$ Diego M. Ruiz, ${ }^{\mathrm{b}}$ Tierry Constantieux, ${ }^{\mathrm{c}}$ Jean Rodriguez, ${ }^{\mathrm{c}}$ Gustavo P. Romanelli*a,b \\ a Centro de Investigación y Desarrollo en Ciencias Aplicadas ‘Dr. Jorge J. Ronco’ (CINDECA-CCT-CONICET), Universidad Nacional de La \\ Plata, Calle 47 No. 257, B1900AJK La Plata, Argentina \\ E-mail: agsathicq@quimica.unlp.edu.ar; E-mail: gpr@quimica.unlp.edu.ar; Fax +54(221)4211353125 \\ b Cátedra de Química Orgánica, Facultad de Ciencias Agrarias y Forestales, Universidad Nacional de La Plata, Calles 60 y 119 s/n, B1904AAN \\ La Plata, Argentina \\ c Institut des Sciences Moléculaires de Marseille-UMR CNRS 7313 iSm2, Aix-Marseille Université Centre Saint Jérôme, Service 531, 13397 \\ Marseille Cedex 20, France
}

\begin{abstract}
A series of trifluoromethylated hexahydropyrimidines was synthesized using Preyssler heteropoly acid $\mathrm{H}_{14} \mathrm{NaP}_{5} \mathrm{~W}_{29} \mathrm{MoO}_{110}$ encapsulated in a silica framework as the catalyst under solvent-free conditions. This synthesis requires short reaction times $(1.5 \mathrm{~h})$ and $80{ }^{\circ} \mathrm{C}$ under solvent-free conditions to obtain good to excellent yields of 18 hexahydropyrimidine derivatives. Preyssler catalyst embedded in the silica matrix, unlike the bulk or supported on silica, is insoluble in polar media such as acetone, ethanol, or methanol, which allows easy removal of the reaction products without affecting catalytic activity.

Key words: fluorinated hexahydropyrimidines, trifluoromethyl derivatives, Preyssler heteropoly acid, encapsulated in a silica framework, solvent-free, multicomponent reactions
\end{abstract}

Heterogeneous catalysts have gained much importance in recent years due to environmental and economic considerations. These heterogeneous catalysts are advantageous over homogeneous catalysts as they can be easily recovered from the reaction mixture by simple filtration and can be reused after activation, thereby making the process economically viable. ${ }^{1}$ Suitable chemistry as applied to chemical processes can be considered as a series of reductions as well as waste, energy, auxiliaries and should always lead to the simplification of the process in terms of the number of chemicals and steps involved. ${ }^{2}$ Due to growing concerns over the adverse influence of organic solvents on the environment, solvent-free organic reactions have attracted the attention of organic chemists. ${ }^{3-5}$

As part of a research project to develop environmentally friendly organic reactions, we used different heteropoly acids in various reactions to prepare heterocycles under greener conditions, including the synthesis of quinoxalines, ${ }^{6}$ flavones, chromones, dihydrocoumarins, ${ }^{7}$ and $N$ sulfonyl-1,2,3,4-tetrahydroisoquinolines. ${ }^{8}$

On the other hand, the creation of molecular complexity and diversity from simple substrates while combining economic aspects with environmental ones constitutes a great challenge in modern organic chemistry, both from academic and industrial points of view. Multicomponent reactions involving domino processes have emerged as powerful tools to reach this near ideal goal. ${ }^{3 a, 9}$

In 1999, Kappe and co-workers discovered that by using a fluorinated acetoacetic ester derivative, for example ethyl trifluoroacetate, the Biginelli reaction takes a different course and a hexahydropyridine is obtained, representing a heterocyclic system of remarkable pharmacological activities. ${ }^{10}$

In particular, fluorine building blocks are important because of their extensive use in the synthesis of drugs covering a wide variety of therapeutic areas. A fluorine atom is similar in size to a hydrogen atom. Thus, the replacement of hydrogen by fluorine is not expected to cause any significant changes in molecular geometry and shape. The high electronegativity of fluorine has a strong effect on the electronic properties of the basic molecules. On a molecular level this allows for the inhibition of some metabolic pathways, including the modulation of membrane permeability and electrostatic interactions with the target site. $^{11}$

The hexahydropyrimidine nucleus is also present in a number of alkaloids, such as the tetraponerines verbamethine and verbametrine. ${ }^{12}$ The preparation of hexahydropyrimidine involves the use of the same catalyst as the one used for the synthesis of dihydropyrimidone (DHPM) $\left[\mathrm{HCl},{ }^{10 \mathrm{~b}}\right.$ PTSA, ${ }^{13}$ sulfamic acid, ${ }^{14}$ benzyltriethylammonium chloride, ${ }^{15}$ chlorotrimethylsilane, ${ }^{12}$ and zirconium(IV) chloride]. ${ }^{16}$

Herein, we report for first time a simple, convenient, efficient, and ecofriendly process for the preparation of trifluoromethylated hexahydropyrimidines from aldehydes, trifluoromethylacetoacetate, and urea or thiourea using heteropoly acids encapsulated in silica frameworks $\left(\mathrm{PCSiO}_{2}\right)$ as a solid catalyst under solvent-free conditions (Scheme 1).

Several reaction conditions were tested in order to obtain the best reaction conditions. We observed that when a mixture of the three components and a catalytic amount of $\mathrm{PCSiO}_{2}$ (100 mg, $0.2 \mathrm{mmol} \%$ of active phase) was stirred 


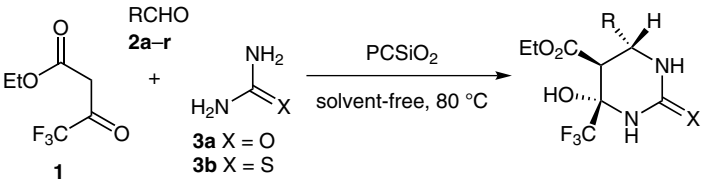

Scheme 1 Synthesis of trifluoromethyl-substituted hexahydropyrimidines

under solvent-free conditions at $80^{\circ} \mathrm{C}$, the corresponding hexahydropyrimidine (Table 1, entry 5) was formed as the only reaction product in $91 \%$ yield with a reaction time of 1.5 hours. It is noteworthy that the reaction yields were slightly lower (Table 1, entry 2) when bulk PC was used $(84 \%)$. In this test, several unidentified side products were detected by TLC. Also, without catalyst the reaction yield was low $(<5 \%$, Table 1 , entry 1$)$, and similarly when the support was used as catalyst and under the same reaction conditions, the yield was only $16 \%$ (Table 1 , entry 4 ).

Table 1 Screening of Preyssler Catalysts in the Fluorinated Hexahydropyrimidine Synthesis

\begin{tabular}{llll}
\hline Entry & Catalyst & Time (h) & Yields (\%) \\
\hline 1 & - & 2 & $<5$ \\
2 & $\mathrm{PC}$ & 2 & 84 \\
3 & $\mathrm{PC}$ & 8 & 62 \\
4 & $\mathrm{SiO}_{2}$ & 2 & 16 \\
5 & $\mathrm{PCSiO}_{2}$ & 1.5 & 91 \\
\hline
\end{tabular}

It is important to note that the catalyst obtained by encapsulation of $\mathrm{PC}$ in the silica framework $\left(\mathrm{PCSiO}_{2}\right)$ is more selective than the bulk catalyst (PC). This can be justified considering the acid strength of the catalysts. The potentiometric titration with $n$-butylamine showed that the acid strength of both catalysts were $833 \mathrm{mV}$ and $425 \mathrm{mV}$, respectively. As shown, a decrease in the acid strength of the catalyst may be correlated with an increase in the reaction selectivity and the disappearance of secondary products such as 3,4-dihydropyrimidinone (classic product of Biginelli reaction). In previous reports, our research group has shown the lowering of acid strength of a heteropoly acid when is incorporated in the silica framework. ${ }^{17}$

Encouraged by the remarkable results obtained with the above reaction and in order to show the generality and scope of this catalytic method, the fluorinated hexahydropyrimidine synthesis of a series of aldehydes was studied under similar conditions. The results are summarized in Table 2. In all of the studied examples, the reaction proceeded smoothly; aromatic aldehydes having either electron-withdrawing or electron-releasing substituents, including hydroxyl, reacted efficiently to give very good to excellent yields of the desired hexahydropyrimidines (Table 2, entries 1-11,87-97\%). Similarly, when thiourea rather than urea was used, the corresponding hexahydro- pyrimidines were obtained in good yields (Table 2 , entries $12-17,80-84 \%$ ).

We also investigated the reuse of the catalyst. For this purpose after completion of the reaction, acetone $(2 \times 1 \mathrm{~mL})$ was added to the semisolid reaction mixture. All the reaction products are very soluble in acetone at room temperature, but the catalyst is insoluble. So it could be separated by simple filtration. The catalyst was dried under vacuum $\left(25^{\circ} \mathrm{C}\right)$. The catalyst was recycled, and the product yields

Table 2 Synthesis of Fluorinated Hexahydropyrimidine Derivatives in a Solvent-Free System at $80^{\circ} \mathrm{C}$ Using Encapsulated Preyssler Heteropoly Acids

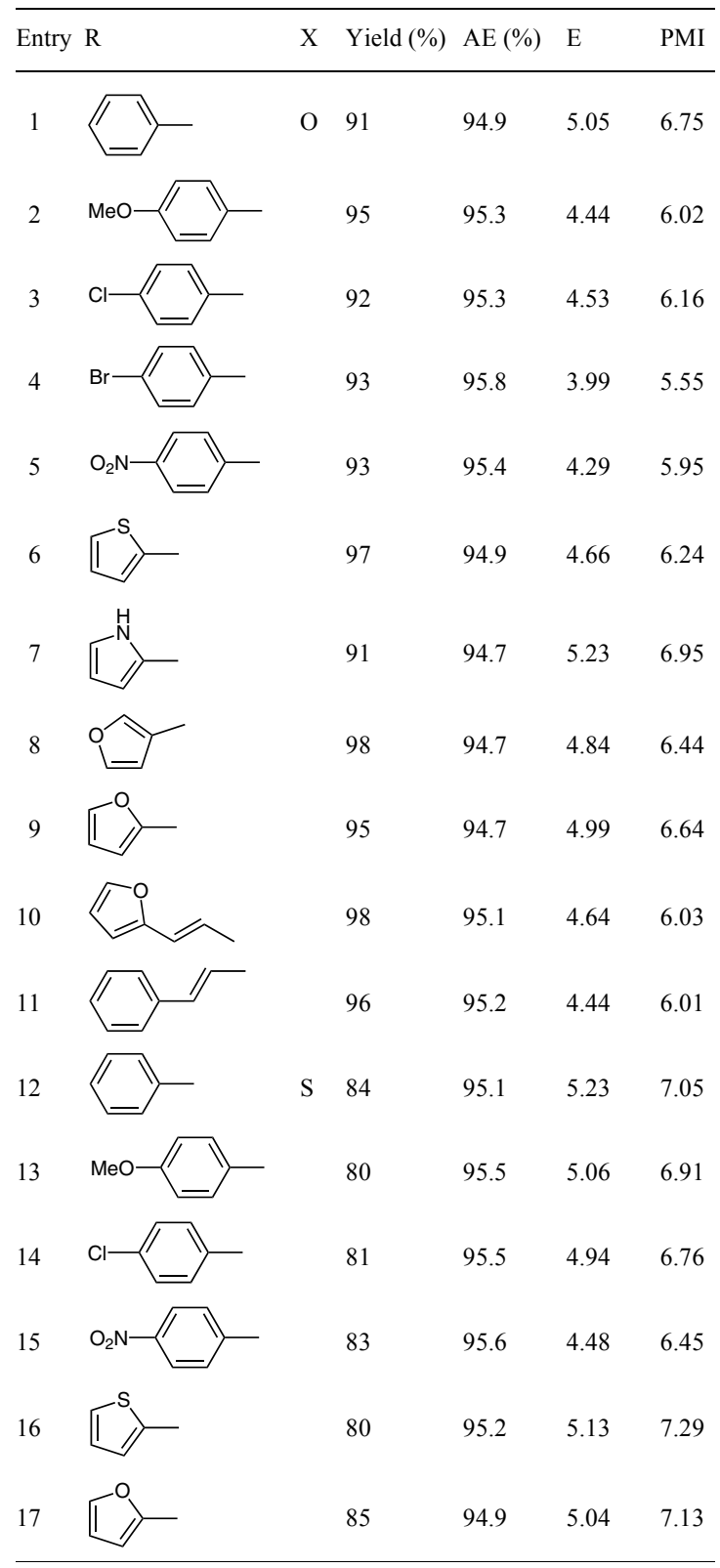


for the first, second, and third reuse using benzaldehyde as substrate were $90 \%, 88 \%$, and $87 \%$.

In order to quantify how much 'greener' the methodology is, the atomic economy (AE), atomic efficiency factor (E), and process mass intensity (PMI) were calculated for each reaction product, and the results are presented in Table 2. We compare these values with the ones previously reported in the literature (Supporting Information), and it is important to note that this methodology is a very suitable method to prepare hexahydropyrimidines.

In conclusion, a very simple and convenient catalytic method was developed for the preparation of fluorinated hexahydropyrimidine derivatives from a multicomponent reaction under solvent-free conditions. The procedure has the advantages of low environmental impact, high yield, high selectivity, short reaction time, and the catalyst can be recycled by simple filtration. The catalyst was washed in polar media such as acetone, and no leaching was observed. The use of an insoluble catalyst instead of soluble inorganic acids contributes to waste reduction. Further investigations about the use of this catalyst in the new heterocyclic synthesis and in the biomass valorization are in progress in our laboratory.

General Procedure for the Synthesis of $\mathrm{PCSiO}_{2}$

$\mathrm{PCSiO}_{2}$ was synthesized by the sol-gel technique. A mixture of Preyssler acid $(1.33 \mathrm{~g}), \mathrm{H}_{2} \mathrm{O}(10 \mathrm{~g})$ and $\mathrm{HCl}(1 \mathrm{~mL} 0.1 \mathrm{M})$ was added to tetraethyl orthosilicate $(26.124 \mathrm{~g})$. The mixture was stirred for 5 $\mathrm{h}$ at r.t. Then the mixture was allowed to stand for $3 \mathrm{~d}$, and after breaking the hydrogel formed with a Teflon stick, it was dried in vacuum for 1 week at r.t. The powder was washed with distilled $\mathrm{H}_{2} \mathrm{O}(3 \times 10 \mathrm{~mL})$ and dried in vacuum. The aqueous phase was analyzed for $\mathrm{W}$ content via ICP, but no $\mathrm{W}$ traces were detected. The $\mathrm{PCSiO}_{2}$ catalyst was characterized by ${ }^{31} \mathrm{P}$ MAS-NMR and FTIR spectroscopy (see Supporting Information), and complete characterization will be reported elsewhere.

General Procedure for the Synthesis of Hexahydropyrimidines A mixture of ethyltrifluoroacetoacetate $(184 \mathrm{mg}, 1 \mathrm{mmol})$, benzaldehyde (281 mg, $1 \mathrm{mmol})$, urea (72 $\mathrm{mg}, 1.2 \mathrm{mmol}$ ), and $\mathrm{PCSiO}_{2}$ $(0.2 \% \mathrm{mmol}$ active phase $)$ was thoroughly mixed and then heated at $80^{\circ} \mathrm{C}$ for $1.5 \mathrm{~h}$ (TLC control). On cooling, the reaction mixture was washed with acetone $(2 \times 1 \mathrm{~mL})$, and the hexahydropyrimidines were filtered and dried under vacuum $\left(25^{\circ} \mathrm{C}\right)$. The crude product was recrystallized to give the pure dihydropyrimidinones.

\section{Acknowledgment}

The authors thank CONICET, ANPCyT, UNLP, Centre National de la Recherche Scientifique (CNRS) and the Université Paul Cézanne d'Aix-Marseille for their financial support. AGS and GPR are members of CONICET.
Supporting Information for this article is available online at http://www.thieme-connect.com/ejournals/toc/synlett.

\section{References}

(1) (a) Beletskaya, I.; Tyurin, V. Molecules 2010, 15, 4792. (b) Corma, A.; Garcia, H. Adv. Synth. Catal. 2006, 348, 1391. (c) Sheldon, R. A. Chem. Soc. Rev. 2012, 41, 1437. (d) Datan, A.; Kulkarni, A.; Torok, B. Green Chem. 2012, 14, 17. (e) Su, D.; Zhang, J.; Frank, B.; Thomas, A.; Wang, X.; Paraknowitsch, J.; Schlog, R. ChemSusChem 2010, 3 , 169.

(2) (a) Watson, W. Green Chem. 2012, 14, 251. (b) Kalidindi, S.; Jagirdar, B. ChemSusChem 2012, 5, 65. (c) Mulvihill, M.; Beach, M.; Zimmerman, E.; Anastas, P. Annu. Rev. Environ. Res. 2011, 36, 271.

(3) (a) Singh, M.; Chowdhury, S. RSC Adv. 2012, 2, 4547. (b) Shearouse, W.; Waddell, D.; Mack, J. Curr. Opin. Drug Discov. Dev. 2009, 12, 772. (c) Kalita, P.; Kumar, R. Microporous Mesoporous Mat. 2012, 149, 1.

(4) Niknam, K.; Saberi, D.; Mohagheghnejad, M. Molecules 2009, 14, 1915.

(5) (a) Timofeeva, M. N. Appl. Catal., A 2003, 256, 19. (b) Romanelli, G.; Autino, J. Mini-Rev. Org. Chem. 2009, 6, 359.

(6) Ruiz, D.; Autino, J.; Quaranta, N.; Vázquez, P.; Romanelli, G. Sci. World J. 2012, 174784.

(7) Bennardi, D.; Ruiz, D.; Romanelli, G.; Baronetti, G.; Thomas, H.; Autino, J. Lett. Org. Chem. 2009, 5, 607.

(8) (a) Pasquale, G.; Ruiz, D.; Autino, J.; Baronetti, G.; Thomas, G.; Romanelli, G. C. R. Chim. 2012, 15, 758. (b) Romanelli, G.; Ruiz, D.; Autino, J.; Giaccio, H. Mol. Diversity 2010, 15 803.

(9) (a) Liéby-Muller, F.; Constantieux, T.; Rodriguez, J. J. Am. Chem. Soc. 2005, 127, 17176. (b) Isambert, N.; Duque, M.; Plaquevent, J.; Génisson, Y.; Rodriguez, J.; Constantieux, T. Chem. Soc. Rev. 2011, 40, 1347.

(10) (a) Kappe, C. O.; Falsone, S. F.; Fabian, W. M. F.; Belaj, F. Heterocycles 1999, 51, 77. (b) Saloutin, V.; Burgart, Y.; Kuzueva, O.; Kappe, C. O.; Chupakhin, O. J. Fluorine Chem. 2000, 103, 17.

(11) Agbaje, O.; Fadeyi, O.; Fadeyi, S.; Myles, L.; Okoro, C. Bioorg. Med. Chem. Lett. 2011, 21, 989.

(12) Ryabukhin, S.; Plaskon, A.; Ostapchuk, E.; Volochyuk, D.; Shishkin, O.; Tolmachev, A. J. Fluorine Chem. 2008, 129, 625.

(13) Zohdi, H.; Rateb, N.; Elnagdy, S. Eur. J. Med. Chem. 2011, $46,5636$.

(14) Li, G.; Wu, C.; Guo, L.; Yang, F. Acta Crystallogr., Sect. E: Struct. Rep. Online 2011, 67, 704 .

(15) Bose, D.; Sudharshan, M.; Chavhan, S. ARKIVOC 2005, (iii), 228.

(16) Reddy, C.; Mahesh, M.; Raju, P.; Babu, T.; Reddy, V. Tetrahedron Lett. 2002, 43, 2657.

(17) Pasquale, G.; Vázquez, P.; Romanelli, G.; Baronetti, G. Catal. Commun. 2012, 18, 115 . 